\title{
Do smartphone applications and activity trackers increase physical activity in adults? Systematic review, meta-analysis and metaregression
}

\author{
Liliana Laranjo (D) ,', Ding Ding (D) ,' Bruno Heleno (D) ,' Baki Kocaballi, ${ }^{3,5}$ \\ Juan C Quiroz, ${ }^{2,6}$ Huong Ly Tong, ${ }^{2}$ Bahia Chahwan, ${ }^{2}$ Ana Luisa Neves, ${ }^{7}$ Elia Gabarron, ${ }^{8}$ \\ Kim Phuong Dao, ${ }^{2}$ David Rodrigues, ${ }^{9}$ Gisela Costa Neves, ${ }^{9}$ Maria L Antunes, ${ }^{10}$ \\ Enrico Coiera (1) ${ }^{2}$ David W Bates ${ }^{11}$
}

\begin{abstract}
- Additional material is published online only. To view, please visit the journal online (http://dx.doi.org/10.1136/ bjsports-2020-102892).
\end{abstract}

For numbered affiliations see end of article.

Correspondence to Dr Liliana Laranjo, Faculty of Medicine and Health Westmead Applied Research Centre, The University of Sydney, Sydney, NSW 2113, Australia; liliana.Laranjo@mq.edu.au

$\mathrm{DD}$ and $\mathrm{BH}$ contributed equally.

Accepted 5 November 2020

Published Online First

21 December 2020

\section{ABSTRACT}

Objective To determine the effectiveness of physical activity interventions involving mobile applications (apps) or trackers with automated and continuous selfmonitoring and feedback.

Design Systematic review and meta-analysis.

Data sources PubMed and seven additional databases, from 2007 to 2020.

Study selection Randomised controlled trials in adults (18-65 years old) without chronic illness, testing a mobile app or an activity tracker, with any comparison, where the main outcome was a physical activity measure. Independent screening was conducted.

Data extraction and synthesis We conducted random effects meta-analysis and all effect sizes were transformed into standardised difference in means (SDM). We conducted exploratory metaregression with continuous and discrete moderators identified as statistically significant in subgroup analyses.

Main outcome measures Physical activity: daily step counts, min/week of moderate-to-vigorous physical activity, weekly days exercised, min/week of total physical activity, metabolic equivalents.

Results Thirty-five studies met inclusion criteria and 28 were included in the meta-analysis ( $n=7454$ participants, 28\% women). The meta-analysis showed a small-to-moderate positive effect on physical activity measures (SDM 0.350, 95\% Cl 0.236 to $0.465, \mathrm{I}^{2}=69 \%$, $\left.T^{2}=0.051\right)$ corresponding to 1850 steps per day $(95 \% \mathrm{Cl}$ 1247 to 2457). Interventions including text-messaging and personalisation features were significantly more effective in subgroup analyses and metaregression. Conclusion Interventions using apps or trackers seem to be effective in promoting physical activity. Longer studies are needed to assess the impact of different intervention components on long-term engagement and effectiveness.

\section{INTRODUCTION}

(C) Author(s) (or their employer(s)) 2021. No commercial re-use. See rights and permissions. Published by BMJ.

To cite: Laranjo L,

Ding $D$, Heleno B,

et al. Br J Sports Med

2021:55:422-432.
Physical activity is essential to the prevention and treatment of multiple chronic conditions ${ }^{12}$ and can prevent premature mortality. ${ }^{3}$ Any intensity of physical activity substantially reduces risk of death in a dose-response manner. ${ }^{4}$ Nonetheless, more than a quarter of adults worldwide are insufficiently active, ${ }^{5}$ and physical inactivity represents a leading cause of death worldwide. ${ }^{6}$ The global pandemic of physical inactivity is responsible for at least $\$ 67.5$ billion of economic burden per year. ${ }^{7}$

Behaviour change interventions to promote physical activity can include several behaviour change strategies and components-so-called behaviour change techniques (BCTs). ${ }^{8}$ Two BCTs seem to be particularly effective: self-monitoring and feedback on behaviour.' ${ }^{9}$ For instance, interventions using pedometers can facilitate self-monitoring and feedback on step counts, having shown significant improvements in the short term (4 months). ${ }^{10} 11$ However, these pedometer interventions are burdensome to maintain, as users have to use a step diary to keep track of their step counts.

In contrast, modern-day smartphone applications (apps) and activity trackers (eg, wearable fitness bands and smartwatches) enable automated and continuous self-monitoring and feedback on physical activity. Current smartphones and trackers enable the burdenless measurement of activity with acceptable accuracy, ${ }^{12}$ as well as allow for continuous access to recorded data (longitudinally and in real time), via apps or the tracker's display. Nevertheless, a major challenge with apps and trackers is their high drop-off rate, ${ }^{13}$ with reports of a third of users of activity trackers abandoning their device in the first 6 months. ${ }^{14}$ It has been suggested that reducing user burden and providing features like goal setting, personalisation and game-like functionality (ie, gamification) may facilitate engagement, promote retention and increase intervention effectiveness. ${ }^{15-17}$

Existing reviews of apps and trackers have not yet focused on seemingly healthy adults ${ }^{18-23}$ and technology enabling automated and continuous self-monitoring and feedback, with apps often still requiring users to connect an accelerometer to a computer periodically via a hardware connection. $^{2022} 24-30$ These reviews of older apps and trackers have shown non-significant ${ }^{22} 2426$ or small-to-moderate positive results 2028 with high heterogeneity, often mixing very different types of populations apart from healthy adults (eg, children, ${ }^{26}$ elderly 222728 and chronic conditions $^{20} \quad 2527 \quad 28$ ). Furthermore, retention and engagement with these interventions, and effectiveness of different intervention features (eg, personalisation and gamification) have seldom been analysed. 
The aim of this systematic review and meta-analysis was to evaluate the characteristics and effectiveness of interventions involving contemporary mobile apps or physical activity trackers (ie, enabling automated and continuous self-monitoring and feedback) in promoting physical activity, as well as in improving engagement and retention, in adults (18-65 years old) without chronic disease. A secondary aim was to explore and compare the effect of specific features in these interventions using metaregression.

\section{METHODS}

This systematic review is reported in accordance with the Preferred Reporting Items for Systematic Reviews and MetaAnalyses statement. ${ }^{31}$ We followed a protocol registered with PROSPERO (CRD42017057854) for a broader review on physical activity, diet and weight loss. This paper focuses on physical activity; papers focusing on weight loss and diet were excluded at the full-text screening stage and will be analysed in a separate publication.

\section{Search strategy}

A search of the literature was performed in January 2017 (and updated continuously up to January 2020) using PubMed, Embase, CINAHL, PsycInfo, SciELO, ACM Digital Library, Cochrane Central Register of Controlled Trials and ClinicalTrials.gov. Articles were included if published between January 2007 and January 2020 since the launch of the first app stores. No language restrictions were applied. Search strings combined free terms (eg, smartphone, application and wearable) and controlled vocabulary (complete search strategy in online supplemental eMethods). Reference lists of relevant articles were also screened. Citations were uploaded to EndNote V.X9, where duplicates were removed.

\section{Study selection criteria}

We included randomised controlled trials (RCTs) where the population of interest was adults aged 18-65 years old without chronic disease; high adiposity or high body mass index (risk factors for chronic disease) were not exclusion criteria. We selected this study population because the relative homogeneity allows for comparing specific features and because youth, the elderly and those living with chronic diseases have different needs, barriers and enablers regarding physical activity that may not generalise to the general population. The intervention included a mobile app or an activity tracker enabling automated and continuous self-monitoring and feedback on physical activity measures. Our definition excludes pedometers and accelerometers if they did not offer ongoing access to tracked measures throughout time (either via the tracker's display or by wirelessly syncing with an app). Given that this definition is compatible with the state-of-the-art in technologies to promote physical activity, we simply refer to them as 'smartphone apps' and 'activity trackers' throughout the paper.

The comparison group was either a true control (eg, given no intervention-usual care, waiting list-or an intervention not including an app or a tracker) or was an active control (ie, receiving a control intervention including an app or a tracker); and the main outcomes were measures of physical activity (online supplemental eTable 1 and eMethods 2).

\section{Screening and data extraction}

Title and abstract screening and full-paper screening were conducted by six pairs of independent investigators. Two investigators extracted information from the included studies into a Microsoft Excel spreadsheet (version 16.43): publication information, mobile technology, intervention characteristics, study duration, participant and setting characteristics, outcomes, behaviour change theories, retention rates (percentage completing follow-up assessment), engagement measures, funding sources, conflicts of interest, incentives for participation, adherence to reporting guidelines, personalisation and gamification features. Coding of BCTs according to the BCT taxonomy ${ }^{8}$ was conducted by three trained investigators. Included studies were assessed independently by two researchers using Cochrane's risk of bias tool (domains assessed: random sequence allocation, allocation concealment, blinding of participants and personnel, blinding of outcome assessment, incomplete outcome data and selective reporting). ${ }^{32} 33$ Disagreements in screening, data extraction and risk of bias assessment were resolved by a third investigator. Data extraction and coding of BCTs were not conducted independently. For multiarm trials, data extraction was conducted for the two arms of interest (online supplemental eMethods 3). Data extraction was complemented with information from protocol papers, trial registrations and emails to authors, as well as known basic features of commercial trackers and mobile apps.

\section{Strategy for data synthesis}

A narrative synthesis was conducted for all studies. Studies for which it was possible to calculate an effect size were combined for a summary effect. Outcomes from cluster RCTs were included when adjusted for the effects of clustering. Whenever a single study reported multiple outcomes, the outcome to be included in the meta-analysis was selected through consensus among the authors following predefined rules to minimise bias (online supplemental eMethods 3).

Continuous outcomes were pooled together and all effect sizes were transformed into the standardised difference in means (SDM) ${ }^{34}$ Estimates of mean physical activity effect sizes were also converted from SDM to number of steps per day for ease of interpretation (online supplemental eMethods 4).

We used random effects models for all analyses; the betweenstudies variance $\left(T^{2}\right)$ was estimated using the method of moments. We used $\mathrm{I}^{2}$ to describe the proportion of the variance in observed effects that is due to variance in true effects. ${ }^{35}$ The presence of publication bias was evaluated by the use of a funnel plot and the Duval and Tweedie trim-and-fill method. ${ }^{35}$ We used the Grading of Recommendations Assessment, Development and Evaluation (GRADE) system for grading the body of evidence. ${ }^{36}$

\section{Sensitivity analyses, subgroup analyses and metaregression} Seven sensitivity analyses were conducted to assess the robustness of the findings (online supplemental eMethods 5). The cause of observed statistical heterogeneity was explored using subgroup analysis. We conducted 27 subgroup analyses, of which 16 were planned and 11 were post hoc (online supplemental eMethods 6). We conducted metaregression with statistically significant moderators identified in subgroup analyses, a dichotomous variable representing studies where the app or tracker was the only difference between intervention and control, and continuous moderators (number of BCTs in the intervention, retention rate and study duration) for hypothesis-generating purposes. $\mathrm{R}^{2}$ was calculated to determine the proportion of total between-study variance explained by the model. Comprehensive Meta-Analysis V.3 was used for all computations. The significance level for all statistical tests was set at a p value of $<0.05$, two-tailed; 95\% CIs were calculated where applicable. 
Patient and public involvement

Although this study contained no direct consumer involvement, post hoc subgroup analyses were informed by previous work where consumer perspectives and needs in a physical activity intervention were explored. ${ }^{37}$ The results from the present study will be disseminated through the institutional websites and press releases.

\section{RESULTS}

The database search retrieved 10548 articles, after 2662 duplicates were removed (figure 1). After title and abstract screening, 10347 articles were excluded. Full-text screening was conducted for the remaining 201 papers; 44 additional articles were found via updates of the database searches and reference lists of included papers. A further 210 articles were excluded (online supplemental eResults 1 ). The kappa statistic was 0.57 (fair agreement) for the title and abstract screening and 0.78 (substantial agreement) for the full-text screening, before consensus agreement was reached (online supplemental eTable 2). Although 35 studies met inclusion criteria, in 7 studies it was not possible to calculate an effect size to include in the meta-analysis (online supplemental eTables 3-5). The final number of included studies was $28 .^{38-65}$ Of these, one was a doctoral thesis ${ }^{40}$ and another was a working paper ${ }^{57}$; the remaining were published articles.

\section{Description of included studies}

The 28 studies were published between 2014 and 2019, and were mainly $(n=20)$ conducted in the USA $39404547-616364$ (table 1). Study duration varied between 2 and 40 weeks (mean duration: 13 weeks). Studies involved a total of 7454 participants, including 2107 (28\%) women; 14 studies had a sample size smaller than 100 , and 17 studies had less than 50 participants in the active intervention arm. In 12 studies, recruitment included only physically inactive or sedentary adults, ${ }^{40-42} 46-48515455575864$ and in 6 studies, recruitment included only overweight or obese individuals. ${ }^{384147505364}$ Risk of bias was assessed as low for at least 4 out of 6 categories in 17 studies $384042-45$ 48-50 52 5356 58 60 61 64 65 (online supplemental eTable 6). In seven articles, the authors declared relevant conflicts of interest ${ }^{38454850535660}$ (three papers had no conflict of interest statement, online supplemental eTable 7). Adherence to reporting guidelines was explicitly mentioned in eight studies ${ }^{40-43} 48495865$ (online supplemental eTable 7). Physical activity outcomes were measured with a research-grade accelerometer in 11 studies, ${ }^{38} 4042-44464751555964$ self-reported (questionnaire) in 3 studies, ${ }^{39} 4163$ and assessed with a mobile app or consumergrade activity tracker in 14 studies ${ }^{45}$ 48-50 52-5456-58 60-62 65 (online supplemental eTable 8 ). Daily step count was the outcome in 21 studies $^{38404243454648-54565759-626465}$ and moderate-to-vigorous physical activity was the outcome in four studies 4447558 ; three studies had different outcomes (all self-reported)-weekly days exercised, total physical activity ( $\mathrm{min} / \mathrm{week}$ ) and metabolic equivalents per week (online supplemental eTable 8). All extracted outcomes are openly available online (https://osf.io/ $\mathrm{d} 3 \mathrm{rnu} /$ ).

Participant engagement with the intervention was mentioned in 18 studies (online supplemental eTable 9). There was inconsistency in metrics reported. The most commonly reported measure across studies was the percentage of daily usage (six studies), ${ }^{414245} 47-49$ which varied between $58.3 \%$ and $97.4 \%$ (mean 79.9, SD 14.5). Four studies reported on engagement changes throughout time, showing progressively

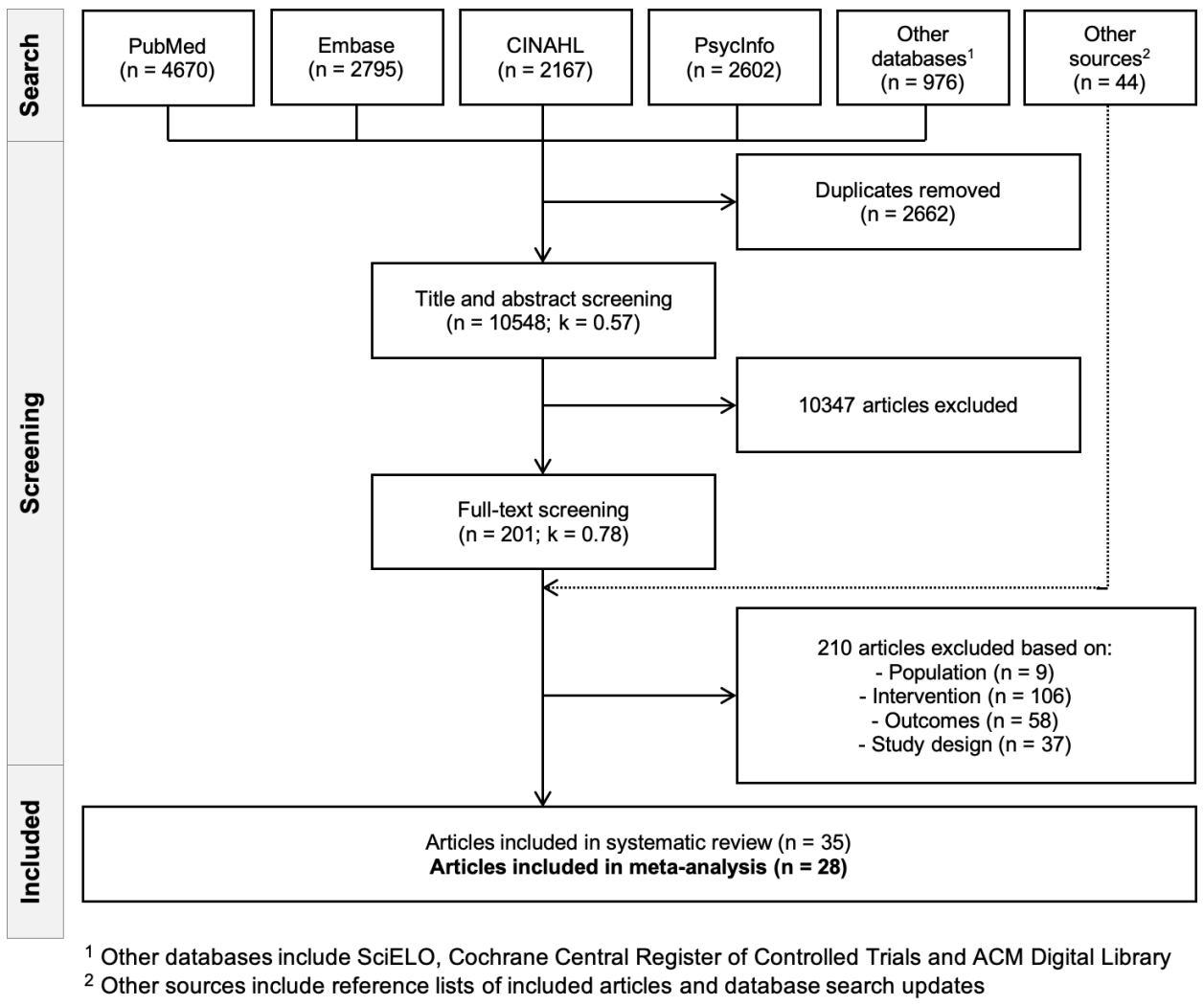

Figure 1 Flowchart of included studies. A total of 28 studies were included in the meta-analysis. ${ }^{1}$ Other databases include SciELO, Cochrane Central Register of Controlled Trials and ACM Digital Library. ${ }^{2}$ Other sources include reference lists of included articles and database search updates. 
Table 1 Characteristics of studies included in the meta-analysis

\begin{tabular}{|c|c|c|c|}
\hline First author, year, country* & Participants $t$ & $\mathrm{~N}(\mathrm{l}, \mathrm{C}), \ddagger$ women $(\mathrm{n})$ & Duration \\
\hline \multicolumn{4}{|l|}{ True control group: no tracker or app component } \\
\hline Wyke, 2019, Netherlands, Norway, Portugal ${ }^{38}$ & Men, $\mathrm{BMI} \geq 27,30-65$ years & $1113(560,553), 0$ & 3months \\
\hline Donoghue, 2018, USA ${ }^{39}$ & $17-50$ years, first year medical students & 3-arm N $120(40,40), 41$ & 10months \\
\hline Pope, 2018, USA ${ }^{40}$ & Inactive, $\S \mathrm{BMI} \geq 18.5,18-35$ years & $38(19,19) ; 28$ & 3months \\
\hline Vandelanotte, 2018, Australia $^{41}$ & Inactive, $\S$ BMI $25-40, \geq 18$ years & $243(121,122), 182$ & 3months \\
\hline Ashton, 2017, Australia ${ }^{42}$ & Men, inactive,§ 18-25 years & $50(26,24), 0$ & 3months \\
\hline Brakenridge, 2016, Australia ${ }^{43}$ & Desk-based office workers & $153(66,87), 70$ & 3months \\
\hline Finkelstein, 2016, Singapore ${ }^{44}$ & $21-65$ years, office workers ( 13 worksites) & 4-arm N $800(203,201), 212$ & 6months \\
\hline Poirier, 2016, USA ${ }^{45}$ & Office workers & $265(133,132), 175$ & 1.5months \\
\hline Ashe, 2015, Canada ${ }^{46}$ & Women, inactive, $75-70$ years & $25(13,12), 25$ & 6months \\
\hline Cadmus-Bertram, 2015, USA ${ }^{47}$ & Women, inactive, ${ }^{* *} \mathrm{BMI} \geq 25$, postmenopause & $51(25,26), 51$ & 4months \\
\hline Martin, 2015, USA ${ }^{48}$ & Inactive, $† \dagger 18-69$ years, CVD prevention centre & 3-arm N $48(16 ; 16) ; 15$ & 5 weeks \\
\hline Thorndike, 2014, USA ${ }^{49}$ & $21-45$ years, medical residents & $104(52,52), 54$ & 1.5 months \\
\hline \multicolumn{4}{|l|}{ Active control with a tracker or app component } \\
\hline Patel, 2019, USA & $\mathrm{BMI} \geq 25$ & 4-arm N $602(150,151), 175$ & 6 months \\
\hline Ellingson, 2019, USA ${ }^{51}$ & Inactive, $\$ 24-65$ years & $91(45,46), 48$ & 3months \\
\hline Zhang, 2019, USA ${ }^{52}$ & Women, 18-35 years, African-American & $91(44,47), 91$ & 3months \\
\hline Patel, 2018, USA ${ }^{53}$ & $\mathrm{BMI} \geq 27$, university staff & 4-arm N $209(44,65), 160$ & 13 weeks \\
\hline Robinson, 2018, USA $^{54}$ & Inactive, $\S 35-69$ years & $63(31,32), 45$ & 5 weeks \\
\hline Fanning, 2017, USA ${ }^{55}$ & Inactive, $^{* *} 30-54$ years & 4-arm N $116(29,87), 93$ & 3months \\
\hline Patel, 2017, USA ${ }^{56}$ & Family members in Framingham Study & $206(102,104), 112$ & 3months \\
\hline John, 2016, USA ${ }^{57}$ & Inactive, $\neq \ddagger$ AchieveMint users & $2055(1027,1028), N R$ & 2 weeks \\
\hline King, 2016, USA ${ }^{58}$ & Inactive ${ }^{* *}$ or sedentary, $\S \S \geq 45$ years & 4 -arm N 95 (22, 27), 36 & 2months \\
\hline Melton, 2016, USA ${ }^{59}$ & African-American women, $18-24$ years & $69(28,41), 69$ & 2 months \\
\hline Patel, 2016, USA (I) & Employees & 4-arm N $304(68,80), 108$ & 13 weeks \\
\hline Patel, 2016, USA (II) ${ }^{61}$ & Employees/family members of employees & 4-arm N $288(64,100), 124$ & 13 weeks \\
\hline Walsh, 2016, Ireland ${ }^{62}$ & Healthy adults & $58(29,29), 40$ & 5 weeks \\
\hline Cowdery, 2015, USA ${ }^{63}$ & $18-69$ years & $40(20,20), 34$ & 3months \\
\hline Wang, 2015, USA ${ }^{64}$ & Inactive, $\S B M I \geq 25,18-69$ years & $67(33,34), 61$ & 1.5 months \\
\hline Glynn, 2014, UK $K^{65}$ & Adults & $90(45,45), 58$ & 2months \\
\hline
\end{tabular}

*Ordered by study year.

†Participant eligibility criteria, organised by gender, level of physical activity, BMI, age, other characteristics, where reported.

‡ln studies with more than two arms, the intervention of interest and control groups were selected as per defined in the methods.

$\S<150-300 \mathrm{~min} /$ week of MVPA.

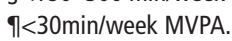

** $<60 \mathrm{~min} /$ week MVPA.

$\dagger \dagger<90 \mathrm{~min} /$ week MVPA.

$\ddagger \ddagger<70$ th percentile for mean daily steps in AchieveMint platform.

$\S \S$ Sitting time $\geq 10$ hours/day.

app, smartphone application; BMI, body mass index; C, control; CVD, cardiovascular disease; I, intervention; MVPA, moderate-to-vigorous physical activity; NR, not reported.

lower engagement with the intervention. ${ }^{43} 445155$ Retention rates varied between $61 \%$ and $100 \%$ for the intervention group (mean 90.5\%, SD 10.2) (online supplemental eTable 9). In 15 studies, participants received incentives for study compliance and completion, most commonly gift vouchers $^{38} 40-424445475052-5456 \quad 58-60$ (online supplemental eTable 10).

\section{Intervention and control group components and BCTs}

Studies were grouped according to whether or not the control group involved a smartphone app or tracker enabling automatic self-monitoring and feedback: true control (12 studies) $)^{38-49}$ or active control (16 studies) ${ }^{50-65}$ (table 2). Most interventions $(\mathrm{n}=20)$ included a physical activity tracker, with or without a mobile app a $^{3845} 51525456575964$ (12 studies included a tracker with an app); eight interventions used a smartphone app without a tracker ${ }^{53} 555860-6365$ (table 2 and online supplemental eTable 11). Other common intervention components included email, ${ }^{39} 4345484953-57$ 59-61 63 human involvement (face-to-face or phone calls) 3842434647495155626465 and text messaging. ${ }^{454853555660616465}$ There were only five studies where the only different components between intervention and control were the tracker or the smartphone app for selfmonitoring and feedback on physical activity. 4041435859

Behaviour change theories were mentioned in 19 studies, ${ }^{38} 40-42$ 44-48 50-52 54-58 62 63 the most common being social cognitive theory ${ }^{40-42} 46525558$ (online supplemental eTable 11). The mean number of BCTs present in interventions was 8.1 (SD 3.2) and in controls it was 2.9 (SD 2.3). Apart from BCTs in the 'feedback and monitoring' group, the most common groups of BCTs present in the intervention were 'goals and planning' and 'reward and threat' (figure 2 and online supplemental eTable 11), and the most frequent techniques were goal setting, ${ }^{38} \quad 3941 \quad 42 \quad 44-48 \quad 50 \quad 51 \quad 54 \quad 55 \quad 60-65$ prompts/cues, ${ }^{43} 45^{48-52} 54 \quad 55$ 57-59 $62-65$ instruction on how to perform the behaviour $384042-44464851545558626365$ and social support. ${ }^{38414244-46515258}$ Gamification or exergames were present in 14 studies $^{38} 3944-4649505355-586063$ (online 
Table 2 Components and BCTs in intervention and control groups ${ }^{*} \dagger$

\begin{tabular}{|c|c|c|c|}
\hline \multirow[b]{2}{*}{ Author } & \multicolumn{2}{|l|}{ Characteristics and BCTs of the intervention } & \multirow[b]{2}{*}{ Characteristics of the control§ } \\
\hline & Tracker and/or app $\ddagger$ & Other intervention components & \\
\hline \multicolumn{4}{|c|}{ True control group: no app or tracker component } \\
\hline Wyke $^{38}$ & Tracker+app: social support and comparison & $\begin{array}{l}\text { Group meetings: goal setting, action planning, } \\
\text { review goals, social support, instruction } \\
\text { on doing the behaviour, info on health } \\
\text { consequences and emotional consequences, } \\
\text { behavioural practice, graded tasks, credible } \\
\text { source, identity associated with new behaviour }\end{array}$ & None \\
\hline Pope $^{40}$ & Tracker+app (Polar) & $\begin{array}{l}\text { Facebook group: instruction on doing the } \\
\text { behaviour }\end{array}$ & Facebook group \\
\hline Vandelanotte $^{41}$ & Tracker (Fitbit) & $\begin{array}{l}\text { Website: goal setting, problem solving, action } \\
\text { planning, feedback, self-monitoring, social } \\
\text { support, info on health consequences }\end{array}$ & Website \\
\hline Brakenridge $^{43}$ & Tracker+app (LUMOback) & $\begin{array}{l}\text { Leaflet, emails, meetings: feedback, instruction } \\
\text { on doing the behaviour, info on health } \\
\text { consequences and on others approval, cues }\end{array}$ & Leaflet, emails, meetings \\
\hline Finkelstein ${ }^{44}$ & Tracker (Fitbit) & $\begin{array}{l}\text { Fitbit website+control: goal setting, social } \\
\text { support and comparison, unspecific reward }\end{array}$ & Leaflets \\
\hline Poirier $^{45}$ & Tracker (Pebble+) & $\begin{array}{l}\text { Website (+SNS), emails, SMS: goal setting, } \\
\text { social support and comparison, cues, graded } \\
\text { tasks, unspecific reward }\end{array}$ & None \\
\hline Martin $^{48}$ & $\underline{\text { Tracker+app (Fitbug) }}$ & $\begin{array}{l}\text { Website, emails, SMS: goal setting, instruction } \\
\text { on doing the behaviour, cues, habit formation, } \\
\text { credible source, unspecific reward }\end{array}$ & None \\
\hline Thorndike ${ }^{49}$ & Tracker (Fitbit): reward & Fitbit website+control & $\begin{array}{l}\text { Gym access, personal training, meetings, } \\
\text { emails }\end{array}$ \\
\hline \multicolumn{4}{|c|}{ Active control with an app or tracker component } \\
\hline Patel, $2019^{50}$ & Tracker (Withings Activité Steel)+app & $\begin{array}{l}\text { SMS/emails, gamification: goal setting, } \\
\text { behavioural contract, commitment, anticipated } \\
\text { regret, social comparison, cues, removal of } \\
\text { aversive stimulus, graded tasks, non-specific } \\
\text { incentive+reward, future punishment, } \\
\text { punishment }\end{array}$ & $\begin{array}{l}\text { Tracker (Withings Activité Steel)+app+SMS/ } \\
\text { emails }\end{array}$ \\
\hline Ellingson ${ }^{51}$ & Tracker+app (Fitbit) & $\begin{array}{l}\text { Motivational interviewing, habit education } \\
\text { (meetings+phone): goal setting, problem } \\
\text { solving; instruction on doing the behaviour, } \\
\text { social support, cues, habit formation }\end{array}$ & Tracker+app (Fitbit) \\
\hline Zhang $^{52}$ & $\begin{array}{l}\text { Tracker (Fitbit)+app+social features: social } \\
\text { support and comparison, cues }\end{array}$ & None & Tracker (Fitbit), app \\
\hline Patel, $2018^{53}$ & App (Moves) & $\begin{array}{l}\text { Combined financial incentives, goal } \\
\text { achievement feedback (SMS/emails): } \\
\text { goal setting, anticipated regret, material } \\
\text { incentive+reward, future punishment }\end{array}$ & $\begin{array}{l}\text { App (Moves), goal achievement feedback } \\
\text { (SMS/emails) }\end{array}$ \\
\hline
\end{tabular}


Table 2 Continued

\begin{tabular}{|c|c|c|c|}
\hline \multirow[b]{2}{*}{ Author } & \multicolumn{2}{|l|}{ Characteristics and BCTs of the intervention } & \multirow[b]{2}{*}{ Characteristics of the control§ } \\
\hline & Tracker and/or app $\neq$ & Other intervention components & \\
\hline Robinson $^{54}$ & Tracker (Fitbit) & $\begin{array}{l}\text { Emails (+incentive reminders), online } \\
\text { resources: goal setting, problem solving, action } \\
\text { planning, instruction on doing the behaviour, } \\
\text { cues, habit formation, graded tasks, reduce } \\
\text { negative emotions, framing/reframing }\end{array}$ & Tracker (Fitbit), emails \\
\hline Fanning ${ }^{55}$ & $\begin{array}{l}\text { App+goal setting, gamification: goal } \\
\text { setting, review goals, discrepancy between } \\
\text { behaviour and goal, instruction on doing } \\
\text { the behaviour, unspecific incentive+reward }\end{array}$ & $\begin{array}{l}\text { Meeting, emails, SMS: goal setting, review } \\
\text { goals, cues, graded tasks, credible source, } \\
\text { unspecific reward }\end{array}$ & App, meeting, emails, SMS, workbook \\
\hline Patel, $2017^{56}$ & App (Moves) OR tracker (Fitbit) & $\begin{array}{l}\text { SMS/emails, gamification: goal setting, } \\
\text { behavioural contract, commitment, social } \\
\text { support, anticipated regret, graded tasks; } \\
\text { material incentive+reward; unspecific incentive } \\
\text { +reward; future punishment }\end{array}$ & $\begin{array}{l}\text { App (Moves) OR tracker (Fitbit), SMS and/ } \\
\text { or emails }\end{array}$ \\
\hline John $n^{57}$ & $\begin{array}{l}\text { App (AchieveMint)+Tracker (Fitbit): material } \\
\text { incentive }\end{array}$ & $\begin{array}{l}\text { Emails (+extra emails about rewards), } \\
\text { monetary reward: cues, cue signalling reward, } \\
\text { material reward }\end{array}$ & App, Fitbit, monetary reward, emails \\
\hline $\mathrm{King}^{58}$ & $\begin{array}{l}\text { Social app: problem solving, social support } \\
\text { and comparison, instruction on doing the } \\
\text { behaviour, cues }\end{array}$ & None & Dietary app \\
\hline Melton ${ }^{59}$ & $\underline{\text { Tracker+app (Jawbone) }}$ & Emails: cues & MyFitnessPal app, emails \\
\hline Patel,2016 $\left.\right|^{60}$ & App (Moves) & $\begin{array}{l}\text { SMS/email/automated voice call, } \\
\text { individual+team incentives: goal setting, social } \\
\text { comparison, material incentive+reward, social } \\
\text { incentive+reward }\end{array}$ & $\begin{array}{l}\text { App (Moves), SMS/email/automated voice } \\
\text { call }\end{array}$ \\
\hline Patel, $2016 \|^{61}$ & App (Moves) & $\begin{array}{l}\text { Feedback on team performance compared with } \\
\text { the 75th percentile (email/SMS): goal setting, } \\
\text { social comparison }\end{array}$ & $\begin{array}{l}\text { App (Moves), feedback on team performance } \\
\text { compared with the 50th percentile }\end{array}$ \\
\hline Walsh $^{62}$ & $\begin{array}{l}\text { App (Accupedo-Pro) with widget: } \\
\text { discrepancy between current behaviour and } \\
\text { goal, cues }\end{array}$ & $\begin{array}{l}\text { Meeting, leaflet: goal setting, instruction } \\
\text { on doing the behaviour, info on health } \\
\text { consequences, demonstration of the behaviour }\end{array}$ & App, Meeting, leaflet \\
\hline Cowdery $^{63}$ & $\begin{array}{l}\text { Apps (exergame+Moves): unspecific } \\
\text { incentive+reward, distraction }\end{array}$ & $\begin{array}{l}\text { Emails: social support, instruction on doing the } \\
\text { behaviour, cues }\end{array}$ & App (Moves) \\
\hline Wang $^{64}$ & Tracker+app (Fitbit) & $\begin{array}{l}\text { SMS, Fitbit website, meeting: goal setting, } \\
\text { problem solving, cues }\end{array}$ & Tracker+app/website (Fitbit), meeting \\
\hline Glynn ${ }^{65}$ & App (Accupedo-Pro) with widget: cues & $\begin{array}{l}\text { Leaflet, SMS, call: goal-setting, instruction } \\
\text { on doing the behaviour, info on health } \\
\text { consequences, cues, credible source }\end{array}$ & App, leaflet, SMS, call \\
\hline
\end{tabular}

\footnotetext{
${ }^{*}$ Components that distinguish the intervention from the control are underlined.

tSome BCTs were abbreviated for conciseness—check online supplemental materials for complete table.

¥By definition of the inclusion criteria, all mHealth technology components include self-monitoring of behaviour and feedback on behaviour, so these BCTs are not shown in intervention columns.

$\S B C T$ f for the control group are available in online supplemental file 1.

app, application; BCT, behaviour change technique; info, information; SMS, short message service; SNS, social networking site.
}

supplemental eTable 12). Personalisation features were mentioned in 12 studies, ${ }^{38} 414244-49545558$ most commonly in the form of personalised goal setting, 3842454758 feedback $^{42} 4446495458$ and content ${ }^{414448}$ (online supplemental eTable 13).

\section{Meta-analysis and metaregression}

The meta-analysis showed a positive effect on physical activity favouring interventions, including smartphone apps or activity trackers versus true and active control (SDM 0.350, 95\% CI 0.236 to $\left.0.465, \mathrm{p}<0.0001, \mathrm{I}^{2}=69 \%, T^{2}=0.051\right)$, corresponding to an increase of 1850 steps per day (95\% CI 1247 to 2457) (figure 3). Despite signs of publication bias in the funnel plot, the Duval and Tweedie trim-and-fill method showed the adjusted estimate remained significant (online supplemental eFigure 1). We conducted seven sensitivity analyses and their results were consistent with the main analysis, showing a significant positive effect on physical activity favouring interventions including smartphone apps or activity trackers (online supplemental eTable 14). Grouping of studies by outcome type did, however, reveal a lower raw difference in means for daily step count (21 studies; 753.2, 95\% CI 440.4 to 970.7). Forest plots of effect sizes ordered by retention rate, study duration and risk of bias are shown in online supplemental eFigures 2-4.

Six of 27 subgroup analyses (3 out of 16 planned analyses) were statistically significant (online supplemental eFigures 5-10 and online supplemental eTable 15), namely, studies where the intervention had goals and planning (SDM 0.446, 95\% CI 0.33 to $0.562, \mathrm{p}<0.0001$ ) or 'graded tasks' (SDM 0.512, 95\% CI 0.337 to $0.687, \mathrm{p}=0.031$ ) BCTs, text messaging (SDM 0.495, $95 \%$ CI 0.335 to $0.654, \mathrm{p}=0.028$ ), personalisation (SDM 0.541, $95 \%$ CI 0.365 to $0.718, \mathrm{p}=0.006$ ), studies where the authors mentioned conflicts of interest (SDM 0.529 , 95\% CI 0.388 to $0.671, p=0.004)$ and studies mentioning behaviour change 


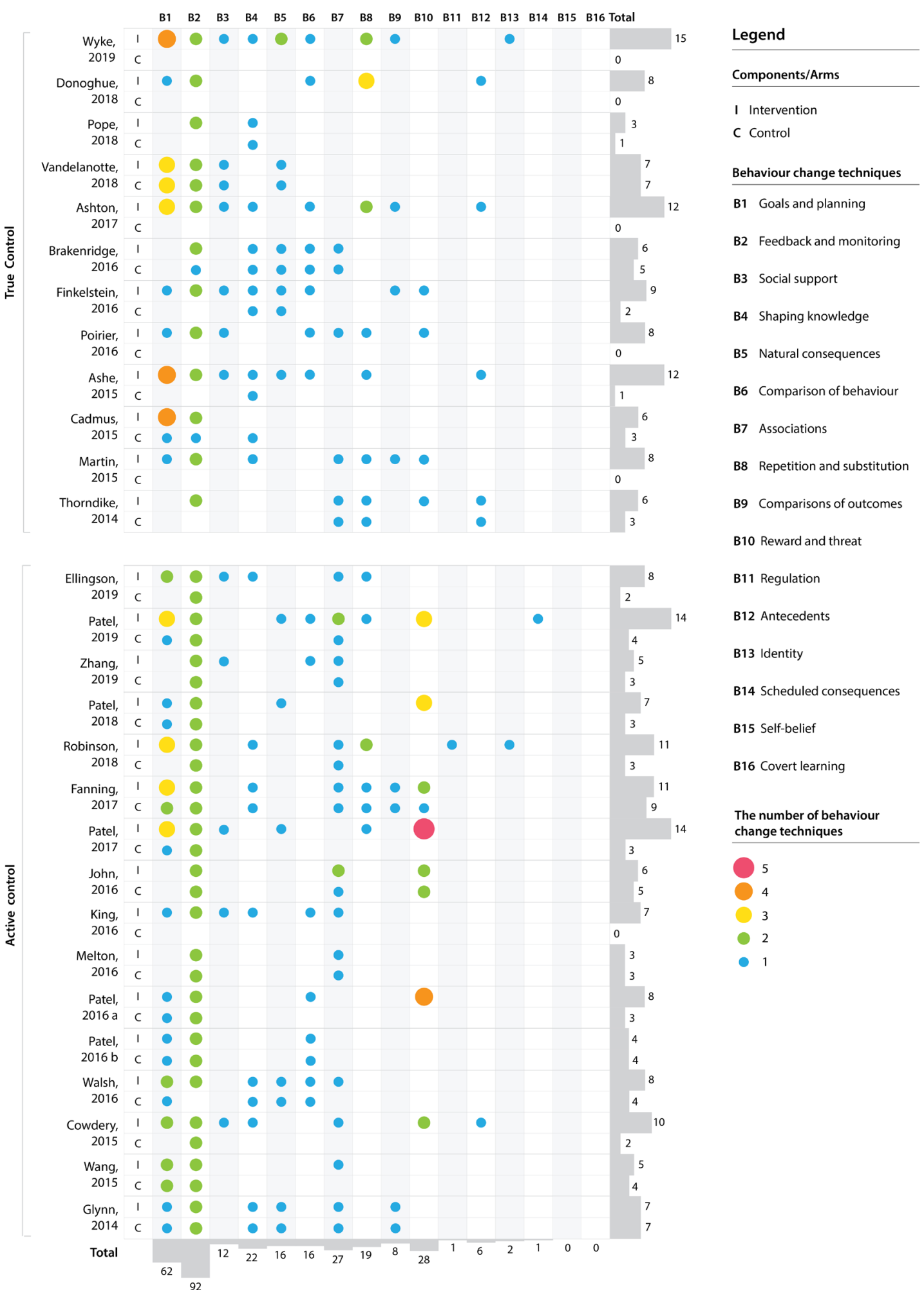

Figure 2 Mapping of $B C T$ s in intervention and control groups of included studies. The most common BCTs present in the intervention were from the 'feedback and monitoring' group (B2, 60 BCTs across all 30 studies), followed by 'goals and planning' (B1, 47 BCTs across 22 studies) and 'reward and threat' (B10, 25 BCTs in 11 studies). BCT, behaviour change technique.

theories (SDM 0.449, 95\% CI 0.312 to $0.587, \mathrm{p}=0.018$ ). Other subgroup analyses were not statistically significant, including analyses of studies where the intervention included an activity tracker or just an app, and studies where the tracker or the app were the only difference between intervention and control groups (online supplemental eTable 15). Heterogeneity was partially explained by differences in intervention components and populations: studies showing an $\mathrm{I}^{2}$ lower than $40 \%$ included those providing action planning or human contact, as well as studies not including activity trackers or focusing on overweight populations (online supplemental eTable 15).

A metaregression model including the moderators that showed significance in the previously mentioned subgroup analyses showed an adjusted $\mathrm{R}^{2}$ of 0.57 (table 3 ). A model including 


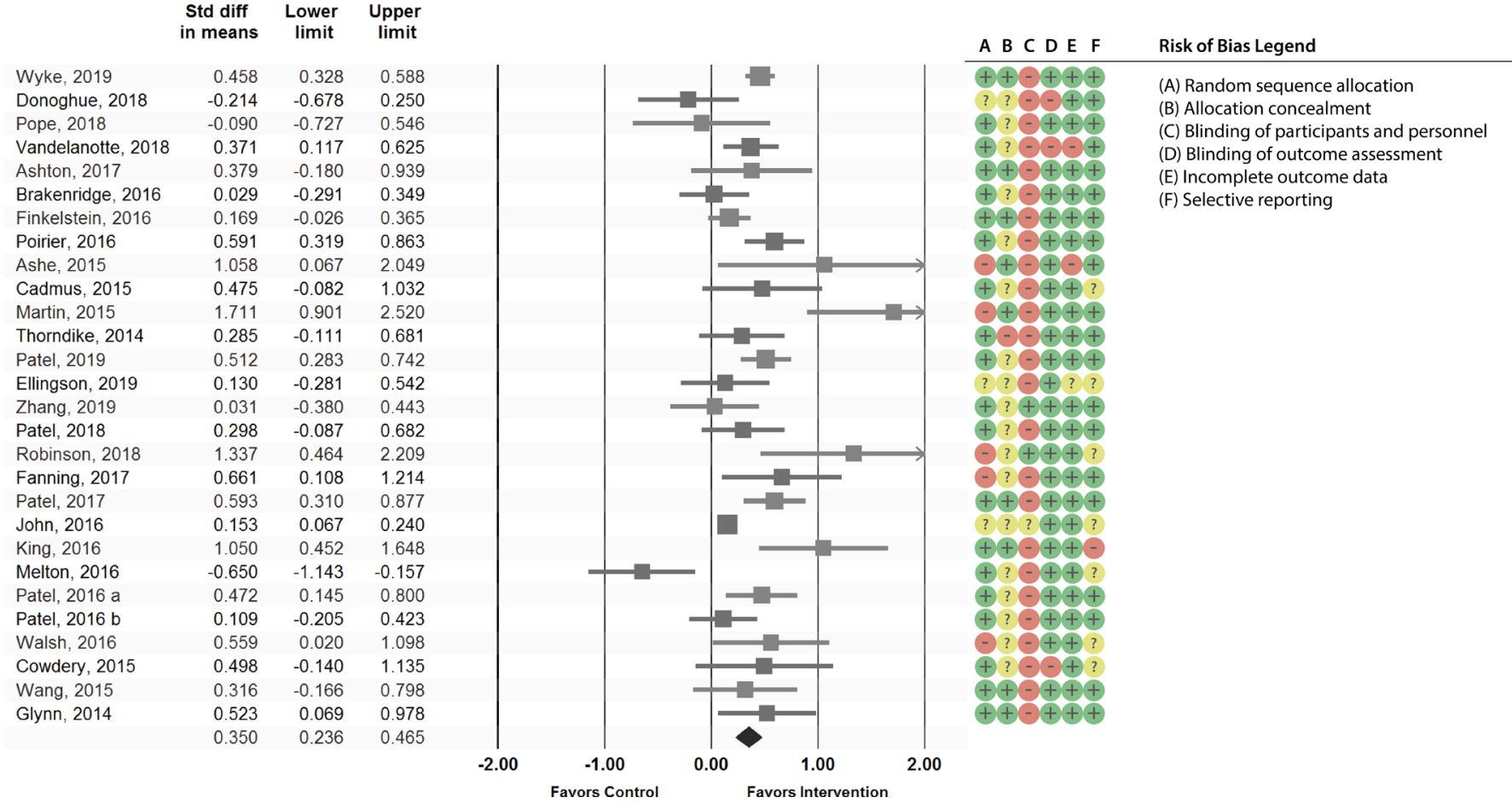

Figure 3 Forest plot of effect sizes and 95\% Cls representing the effect of interventions involving mobile applications or activity trackers in increasing physical activity (random effects model) with risk of bias assessment. The meta-analysis showed a positive effect on physical activity favouring interventions, including smartphone apps or activity trackers (SDM $0.350,95 \% \mathrm{Cl} 0.236$ to $0.465, p<0.0001, I^{2}=69 \%, T^{2}=0.051$ ), corresponding to an increase of 1850 steps per day $(95 \% \mathrm{Cl} 1247$ to 2457$)$. Note: size of squares is proportional to study sample size. SDM, standardised difference in means.

only the significant variables from the previous model, as well as two additional ones-retention rate in the intervention group and study duration-showed an adjusted $\mathrm{R}^{2}$ of 0.64 , but study duration was not significant. A model replacing study duration with a dichotomous variable representing studies where the app or tracker were the only difference between intervention and control showed an adjusted $\mathrm{R}^{2}$ of 0.71 , explaining $71 \%$ of the variance in effectiveness. Overall, text messaging, personalisation, and retention rate in the intervention were all significantly associated with intervention effectiveness, consistently across several models.

\section{DISCUSSION}

\section{Main findings}

This is the first systematic review and meta-analysis of physical activity RCTs testing mobile apps or activity trackers that enable automated and continuous self-monitoring and feedback, in adults without chronic disease. Our findings suggest that interventions using apps or trackers have small-to-moderate effects on physical activity at a mean follow-up of 13 weeks, with an average increase of 1850 steps per day, compared with control. The available evidence is of low-to-moderate quality according to the GRADE system ${ }^{66}$ and should be interpreted within the context of existing heterogeneity and publication bias. However, adjusted results accounting for the presence of publication bias remained significant.

Interventions including text-messaging and personalisation features showed higher effectiveness, with moderate effect sizes. Some variables were significantly associated with higher effect sizes in subgroup analysis but not in the metaregression: interventions including BCTs from the goals and planning group or graded tasks, studies mentioning behaviour change theories and studies mentioning conflicts of interest. Retention rate in the intervention was significantly associated with intervention effectiveness. Engagement measures were seldom mentioned and varied between studies.

\section{Comparison with existing literature}

We found a significant improvement in physical activity with apps and trackers, consistent with several previous metaanalyses focusing on older mobile technologies. ${ }^{10} 11202528$ 67-69 Our meta-analysis included a higher number of RCTs (28 vs an average of 17) and showed lower heterogeneity than other metaanalyses on mobile technologies ( $\mathrm{I}^{2}$ of $69 \%$ vs an average of

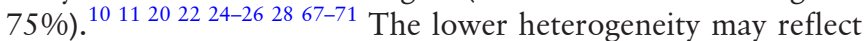
the specificity of our inclusion criteria regarding population selection (adults without chronic disease) and the intervention (smartphone app or activity tracker enabling automated and continuous self-monitoring and feedback).

This study is consistent with previous work showing higher intervention effectiveness with the use of self-regulation techniques (self-monitoring, feedback and goal setting). ${ }^{9} 1172$ Our review expands on this prior work by showing that automating self-monitoring and feedback does not seem to decrease intervention effectiveness, which could happen due to the lower effort and attention required from people to monitor their behaviour. In fact, lowering user burden may indeed contribute to higher engagement and effectiveness by decreasing the 'costs' of the intervention (such as the 'opportunity costs' of doing other valued activities). ${ }^{73}$ Self-regulation techniques are recognisably important in promoting physical activity, ${ }^{911} 72$ and selfregulation is a crucial concept in social cognitive theory, the 
Table 3 Metaregression

\begin{tabular}{|c|c|c|c|}
\hline Covariate $^{*} \ddagger \ddagger$ & Coefficient $(95 \% \mathrm{Cl})$ & $P$ value & $R^{2}$ analogue \\
\hline \multicolumn{4}{|l|}{ Model 0} \\
\hline Intercept & $-0.128(-0.34$ to 0.084$)$ & 0.237 & \multirow[t]{7}{*}{0.57} \\
\hline Goals and planning & $0.05(-0.041$ to 0.141$)$ & 0.281 & \\
\hline Text messaging & 0.365 (0.107 to 0.624$)$ & 0.006 & \\
\hline Personalisation & 0.252 (0.033 to 0.47$)$ & 0.024 & \\
\hline Conflicts of interest & $0.072(-0.222$ to 0.366$)$ & 0.631 & \\
\hline Graded tasks & $-0.132(-0.424$ to 0.159$)$ & 0.374 & \\
\hline Behaviour change theories & $0.24(-0.004$ to 0.484$)$ & 0.054 & \\
\hline \multicolumn{4}{|l|}{ Model 1} \\
\hline Intercept & $-1.054(-1.875$ to -0.232$)$ & 0.012 & \multirow[t]{5}{*}{0.67} \\
\hline Text messaging & 0.302 (0.112 to 0.492$)$ & 0.002 & \\
\hline Personalisation & $0.365(0.16$ to 0.57$)$ & 0.001 & \\
\hline Number of BCTs in the intervention & $0.02(-0.007$ to 0.047$)$ & 0.151 & \\
\hline Retention in the intervention & $0.011(0.002$ to 0.02$)$ & 0.021 & \\
\hline \multicolumn{4}{|l|}{ Model 2} \\
\hline Intercept & $-1.081(-1.914$ to -0.248$)$ & 0.011 & \multirow[t]{4}{*}{0.64} \\
\hline Text messaging & 0.334 (0.147 to 0.522$)$ & 0.001 & \\
\hline Personalisation & $0.427(0.236$ to 0.619$)$ & $<0.001$ & \\
\hline Retention rate in the intervention & 0.012 (0.004 to 0.02$)$ & 0.006 & \\
\hline \multicolumn{4}{|l|}{ Model 3} \\
\hline Intercept & $-1.058(-1.925$ to -0.19$)$ & 0.017 & \multirow[t]{5}{*}{0.64} \\
\hline Text messaging & $0.32(0.127$ to 0.512$)$ & 0.001 & \\
\hline Personalisation & $0.445(0.252$ to 0.639$)$ & $<0.001$ & \\
\hline Retention rate in the intervention & $0.013(0.004$ to 0.022$)$ & 0.005 & \\
\hline Study duration & $-0.007(-0.019$ to 0.004$)$ & 0.192 & \\
\hline \multicolumn{4}{|l|}{ Model 4} \\
\hline Intercept & $-2.077(-3.395$ to -0.759$)$ & 0.002 & \multirow[t]{5}{*}{0.71} \\
\hline Text messaging & $0.422(0.222$ to 0.623$)$ & $<0.001$ & \\
\hline Personalisation & $0.49(0.293$ to 0.686$)$ & $<0.001$ & \\
\hline Retention rate in the intervention & 0.022 (0.009 to 0.036$)$ & 0.001 & \\
\hline $\begin{array}{l}\text { Studies where the app or tracker was the only difference between intervention } \\
\text { and control }\end{array}$ & $0.374(-0.005$ to 0.752$)$ & 0.053 & \\
\hline
\end{tabular}

Multivariate metaregression models with statistically significant moderators identified in subgroup analyses, a dichotomous variable representing studies where the app or tracker was the only difference between intervention and control, and continuous moderators (number of BCTs in the intervention, retention rate and study duration). Statistically significant moderators were kept in successive models. $R^{2}$ was calculated to determine the proportion of total between-study variance explained by the model.

Italicised numbers correspond to statistically significant $\mathrm{p}$ values.

${ }^{*}$ Goals and planning: studies where the intervention includes BCTs in this category.

tText messaging: studies where the intervention includes text messaging.

¥Personalisation: studies mentioning personalisation in the intervention.

$\S$ Conflicts of interest: studies where the authors mention conflicts of interest.

ๆGraded tasks: studies where the intervention included this BCT.

**Behaviour change theories: studies mentioning use of behaviour change theories.

††Reference for all dichotomous variables: remaining studies.

$¥ ¥$ Retention rate: retention rate in the intervention group (continuous variable).

$\mathrm{BCT}$, behaviour change technique.

most commonly mentioned theory in our study and related reviews. ${ }^{24}$ The higher prevalence of social cognitive theory and self-regulation techniques in our review may also explain our finding that interventions mentioning (ie, being based on) behaviour change theories were more effective, with previous meta-analyses suggesting that effectiveness may be more influenced by the specific BCTs used in an intervention than merely by the stated use of theory. ${ }^{74}$

As in other reviews, we found higher effectiveness of interventions including text messaging, ${ }^{75}$ suggesting that this longstanding delivery mode continues to play an important role in behavioural informatics. Text messaging allows the delivery of prompts and cues, a BCT associated with behaviour maintenance. ${ }^{76}$ Future research should explore whether the effect of text messages can be explained by their higher intrusiveness when compared with smartphone notifications (which can be switched off more easily). Additional studies with a longer duration should also explore the role of different components and BCTs in promoting engagement ${ }^{77}$ and intervention effectiveness in the long term.

Our study showed a higher average retention rate than the only other meta-analysis reporting this measure $(90.5 \%$ vs $80 \%) .{ }^{11}$ In our analysis, retention was associated with effectiveness, whereas study duration was not. Furthermore, four studies reported on engagement changes over time, showing progressively lower usage 43445155 despite their short duration-a phenomenon known as the law of attrition of health informatics interventions. ${ }^{78}$ Only one of these studies found a statistically 
significant improvement in physical activity at the end of the intervention, ${ }^{55}$ which suggests the importance of continued engagement for effectiveness. It thus remains unclear what the right 'dose' of app or tracker usage may be, or how it might vary for different people and circumstances. Future studies should consistently report engagement measures to allow future evaluation of the dose-response relationship between app or tracker usage and effectiveness.

Personalisation seems promising in promoting effective engagement with behaviour change interventions. ${ }^{73} \quad 7980$ Previous reviews of computer-tailored interventions to promote behaviour change have found higher effectiveness of interventions providing tailored content, that is, selecting communication content using data-driven decision rules. ${ }^{81}$ Recent developments in artificial intelligence may help leverage the richness of data routinely collected by smartphones and build machine learning models that optimise intervention content, timing and delivery, based on users' preferences, behavioural patterns, and other individual and contextual data. ${ }^{82-84}$ In the future, mobile physical activity interventions may be able to deliver a core set of universally effective BCTs (eg, self-regulation), with additional techniques and features being personalised. Future research should explore users' perspectives on personalisation and the potential downsides resulting from sharing large volumes of personal data for that purpose.

\section{Strengths and limitations}

Our study has several strengths. Our search strategy included peer-reviewed and grey literature. There was substantial agreement in full-text screening. Given that data extraction was hampered by incomplete intervention descriptions, with most studies not adhering to reporting guidelines, we complemented data extraction with information from protocol papers, registrations and emails to authors, as well as known basic features of commercial trackers and mobile apps. Data extraction was extensive and included coding of BCTs by three trained investigators, following the BCT taxonomy. ${ }^{8}$ Several sensitivity analyses were consistent with our main results. Our reporting of retention and engagement metrics and our analysis of the

\section{What is already known}

Waist-worn pedometers can increase physical activity in the short term but are burdensome to use. Reviews of apps and trackers have shown inconsistent results, with high heterogeneity. Existing reviews of apps and trackers have not yet focused on healthy adults and on state-of-the-art technology, enabling automated and continuous selfmonitoring and feedback.

\section{What are the new findings}

- Interventions using contemporary mobile apps or physical activity trackers are effective in promoting physical activity, with a statistically significant effect size of public health relevance. These interventions were more effective when including text-messaging or personalisation features. These results are valuable to clinicians, who may prescribe apps and trackers as part of a shared decision-making process to individuals who seem ready to make behavioural changes. effectiveness of different features within the interventions are the most comprehensive to date.

Our review also has some limitations: (1) the search strategy was not peer reviewed; (2) data extraction and coding were not conducted independently and we could not measure intercoder agreement; (3) our coding of personalisation features was based on authors' mention of this term or synonyms; (4) subgroup analyses and meta-regression should be interpreted as exploratory findings due to the possibility of mass significance and uncontrolled confounding; (5) there was considerable heterogeneity, which was partially explained by differences in intervention components and population; (6) there were changes from the protocol, which are acknowledged in the methods and supplements; (7) generalisation of our results to the female population is limited, given that only $28 \%$ of participants were women (due to the inclusion of a few large-scale studies targeting only men).

\section{Implications}

Interventions using smartphone apps or activity trackers seem promising from a clinical and public health perspective, promoting a significant step count increase of 1850 steps/day. These results are of public health importance according to recent evidence showing that any physical activity, regardless of intensity, is associated with lower mortality risk in a dose-response manner ${ }^{85}$ and that an increase of 1700 steps/day is significantly associated with lower mortality rates. ${ }^{86}$

Apps and trackers are becoming ubiquitous in people's daily lives, with smartphone ownership surpassing three-quarters of the population and activity trackers being used by one-third of adults in the USA and UK. ${ }^{87}$ Despite growing access to these technologies, it is important to ensure that the needs of diverse groups are being met by closing the digital divide, promoting digital health literacy and fostering inclusive design strategies. ${ }^{89}$ Wide reach to different population groups is key to guaranteeing that improvements in physical activity from these interventions generate large effects at the population level, without worsening health inequities.

Enhancing the value of these interventions to consumers may boost long-term engagement and effectiveness, further increasing their impact. Promoting engagement beyond the initial 'novelty phase' is dependent on user experience, overall utility, and the ability to integrate with other devices and services. ${ }^{14}$ Integrating sensor data from apps and trackers with electronic health record data are also likely to be useful for patients and clinicians. This is now possible with the Apple Health app, which is able to pull in health data from healthcare institutions, ${ }^{12}$ operating as a personal health record. Such innovations, adding value to consumers, have the potential to spark a new generation of precision public health interventions.

The prescription of smartphone apps or activity trackers by clinicians to promote physical activity may extend the benefits of these interventions beyond the 'worried well' early adopters. $^{9091}$ Primary care behaviour counselling interventions to promote physical activity are known to consistently improve important intermediate health outcomes, with evidence of a dose-response. ${ }^{92}$ Given increasing time constraints in clinical practice, a brief intervention during the consultation may consist of prescribing an app or tracker, as part of a shared decision-making process, to individuals who seem ready to make behavioural changes. 


\section{CONCLUSION}

We performed a systematic review and meta-analysis of RCTs and found that interventions using smartphone apps or physical activity trackers have a significant small-to-moderate effect in increasing physical activity (1850 steps daily). These interventions were more effective when including text-messaging or personalisation features. Given the wide and increasing reach of smartphones, even modest improvements in physical activity can produce large effects at the population level. Longer-duration studies with more diverse populations should explore long-term effectiveness and sustained engagement.

\author{
Author affiliations \\ ${ }^{1}$ Faculty of Medicine and Health, Westmead Applied Research Centre, The University \\ of Sydney, Sydney, New South Wales, Australia \\ ${ }^{2}$ Centre for Health Informatics - Australian Institute of Health Innovation, Macquarie \\ University, Sydney, New South Wales, Australia \\ ${ }^{3}$ Faculty of Medicine and Health, The University of Sydney, Sydney, New South Wales, \\ Australia \\ ${ }^{4}$ CEDOC, Chronic Diseases Research Centre, NOVA Medical School, Faculdade de \\ Ciências Médicas, Lisbon, Portugal \\ ${ }^{5}$ Faculty of Engineering and IT, University of Technology Sydney, Sydney, New South \\ Wales, Australia \\ ${ }^{6}$ Centre for Big Data Research in Health, University of New South Wales, Sydney, \\ New South Wales, Australia \\ ${ }^{7}$ Institute of Global Health Innovation, Imperial College London, London, UK \\ ${ }^{8}$ Norwegian Centre for Integrated Care and Telemedicine, University Hospital of \\ North Norway, Tromso, Norway \\ ${ }^{9}$ Nova Medical School, Universidade Nova de Lisboa, Lisboa, Portugal \\ ${ }^{10}$ Escola Superior Tecnologias da Saude, Instituto Politécnico de Lisboa, Lisboa, \\ Portugal \\ ${ }^{11}$ Division of General Internal Medicine and Primary Care, Brigham and Women's \\ Hospital, Boston, Massachusetts, USA
}

\section{Twitter Liliana Laranjo @LilianaLaranjo and Ding Ding @DrMelodyDing}

Acknowledgements We thank Annie Y S Lau, Monique Lepouris and Keyu Wang for help with title and abstract screening.

Contributors The corresponding author (LL) attests that all listed authors meet authorship criteria and that no others meeting the criteria have been omitted. LL is the guarantor. Conception and design of the work: LL; database searching: LL, $B C, M L A$; title, abstract and full-text screening: $L L, B C, B H, D R, A L N, E G, H L T, M L A$ outcome data extraction: $\mathrm{LL}, \mathrm{BH} ; \mathrm{BCT}$ coding: $\mathrm{LL}, \mathrm{EG}, \mathrm{HLT}$; risk of bias: $\mathrm{LL}, \mathrm{BH}, \mathrm{ALN}$; figure 1: $B C, L L$; figures 2 and $3: B K, L L ;$ data analysis and interpretation: $L L, B H$, $D D, D W B, J C Q, E C, D R, H L T, K P D, G C N$; first draft: LL; critical revision of drafts for important intellectual content: LL, DD, DWB, BH, BK, JCQ, HLT, KPD, DR, EG, ALN GCN MLA, BC, EC; final approval of the version to be published: LL, DD, DWB, BH, $B K$, JCQ, HLT, KPD, DR, EG, ALN, GCN, MLA, BC, EC.

Funding This research was supported by the National Health and Medical Research Council (grant APP1134919, Centre for Research Excellence in Digital Health). The funder had no role in the design and conduct of the study; collection, management, analysis and interpretation of the data; and preparation, review or approval of the manuscript.

\section{Competing interests None declared.}

\section{Patient consent for publication Not required.}

Provenance and peer review Not commissioned; externally peer reviewed.

Data availability statement The study-specific summary data included in the meta-analysis can be obtained from the corresponding author (liliana.laranjo@mq edu.au).

Supplemental material This content has been supplied by the author(s). It has not been vetted by BMJ Publishing Group Limited (BMJ) and may not have been peer-reviewed. Any opinions or recommendations discussed are solely those of the author(s) and are not endorsed by BMJ. BMJ disclaims all liability and responsibility arising from any reliance placed on the content. Where the content includes any translated material, BMJ does not warrant the accuracy and reliability of the translations (including but not limited to local regulations, clinical guidelines, terminology, drug names and drug dosages), and is not responsible for any error and/or omissions arising from translation and adaptation or otherwise.

\section{ORCID iDs}

Liliana Laranjo http://orcid.org/0000-0003-1020-3402

Ding Ding http://orcid.org/0000-0001-9850-9224
Bruno Heleno http://orcid.org/0000-0002-3943-1858

Enrico Coiera http://orcid.org/0000-0002-6444-6584

\section{REFERENCES}

1 Kyu HH, Bachman VF, Alexander LT, et al. Physical activity and risk of breast cancer, colon cancer, diabetes, ischemic heart disease, and ischemic stroke events: systematic review and dose-response meta-analysis for the global burden of disease study 2013. BMJ 2016;354:i3857.

2 Arem H, Moore SC, Patel A, et al. Leisure time physical activity and mortality: a detailed pooled analysis of the dose-response relationship. JAMA Intern Med 2015; 175:959-67.

3 Lear SA, Hu W, Rangarajan S, et al. The effect of physical activity on mortality and cardiovascular disease in 130000 people from 17 high-income, middle-income, and low-income countries: the PURE study. Lancet 2017;390:2643-54.

4 Ekelund U, Tarp J, Steene-Johannessen J, et al. Dose-Response associations between accelerometry measured physical activity and sedentary time and all cause mortality: systematic review and harmonised meta-analysis. BMJ 2019;366:14570.

5 Guthold R, Stevens GA, Riley LM, et al. Worldwide trends in insufficient physical activity from 2001 to 2016: a pooled analysis of 358 population-based surveys with 1.9 million participants. Lancet Glob Health 2018;6:e1077-86.

$6 \mathrm{Kohl} \mathrm{HW}$, Craig CL, Lambert EV, et al. The pandemic of physical inactivity: global action for public health. Lancet 2012;380:294-305

7 Ding D, Lawson KD, Kolbe-Alexander TL, et al. The economic burden of physical inactivity: a global analysis of major non-communicable diseases. Lancet 2016;388:1311-24.

8 Michie S, Richardson M, Johnston M, et al. The behavior change technique taxonomy (V1) of 93 hierarchically clustered techniques: building an international consensus for the reporting of behavior change interventions. Ann Behav Med 2013:46:81-95.

9 Michie S, Abraham C, Whittington C, et al. Effective techniques in healthy eating and physical activity interventions: a meta-regression. Health Psychol 2009;28:690-701.

10 Kang M, Marshall SJ, Barreira TV, et al. Effect of pedometer-based physical activity interventions: a meta-analysis. Res Q Exerc Sport 2009;80:648-55.

11 Bravata DM, Smith-Spangler C, Sundaram V, et al. Using pedometers to increase physical activity and improve health: a systematic review. JAMA 2007;298:2296-304

12 Sim I. Mobile devices and health. N Engl J Med 2019;381:956-68.

13 Simblett S, Greer B, Matcham F, et al. Barriers to and facilitators of engagement with remote measurement technology for managing health: systematic review and content analysis of findings. J Med Internet Res 2018;20:e10480.

14 Ledger D, McCaffrey D. Inside Wearables: how the science of human behavior change offers the secret to long-term engagement. Endeavour Partners LLC 2014.

15 Tudor-Locke C, Lutes L. Why do pedometers work?: a reflection upon the factors related to successfully increasing physical activity. Sports Med 2009;39:981-93.

16 Higgins JP. Smartphone applications for patients' health and fitness. Am J Med 2016;129:11-19.

17 Cotton V, Patel MS. Gamification use and design in popular health and fitness mobile applications. Am J Health Promot 2019;33:448-51.

18 Davergne T, Pallot A, Dechartres A, et al. Use of wearable activity Trackers to improve physical activity behavior in patients with rheumatic and musculoskeletal diseases: a systematic review and meta-analysis. Arthritis Care Res 2019;71:758-67.

19 Braakhuis HEM, Berger MAM, Bussmann JBJ. Effectiveness of healthcare interventions using objective feedback on physical activity: a systematic review and meta-analysis. $J$ Rehabil Med 2019:51:151-9.

20 Hodkinson A, Kontopantelis E, Adeniji C, et al. Accelerometer- and Pedometer-Based physical activity interventions among adults with cardiometabolic conditions: a systematic review and meta-analysis. JAMA Netw Open 2019;2:e1912895.

21 Kirk MA, Amiri M, Pirbaglou M, et al. Wearable technology and physical activity behavior change in adults with chronic cardiometabolic disease: a systematic review and meta-analysis. Am J Health Promot 2019:33:778-91.

22 Yerrakalva D, Yerrakalva D, Hajna S, et al. Effects of mobile health APP interventions on sedentary time, physical activity, and fitness in older adults: systematic review and meta-analysis. J Med Internet Res 2019;21:e14343.

23 Oliveira S, Sherrington C, RYZ E, et al. Effect of interventions using physical activity trackers on physical activity in people aged 60 years and over: a systematic review and meta-analysis. Br J Sports Med 2019.

24 Romeo A, Edney S, Plotnikoff R, et al. Can smartphone Apps increase physical activity? systematic review and meta-analysis. J Med Internet Res 2019;21:e12053.

25 Feter N, Dos Santos TS, Caputo EL, et al. What is the role of smartphones on physical activity promotion? A systematic review and meta-analysis. Int J Public Health 2019;64:679-90.

26 Flores Mateo G, Granado-Font E, Ferré-Grau C, et al. Mobile phone Apps to promote weight loss and increase physical activity: a systematic review and meta-analysis. J Med Internet Res 2015;17:e253.

27 Lewis ZH, Lyons EJ, Jarvis JM, et al. Using an electronic activity monitor system as an intervention modality: a systematic review. BMC Public Health 2015;15:585.

28 Gal R, May AM, van Overmeeren EJ, et al. The effect of physical activity interventions comprising Wearables and smartphone applications on physical activity: a systematic review and meta-analysis. Sports Med Open 2018;4:42. 
29 Lynch C, Bird S, Lythgo N, et al. Changing the physical activity behavior of adults with fitness Trackers: a systematic review and meta-analysis. Am J Health Promot 2020;34:418-30.

30 Brickwood K-J, Watson G, O'Brien J, et al. Consumer-Based wearable activity Trackers increase physical activity participation: systematic review and meta-analysis. JMIR Mhealth Uhealth 2019;7:e11819.

31 Liberati A, Altman DG, Tetzlaff J, et al. The PRISMA statement for reporting systematic reviews and meta-analyses of studies that evaluate healthcare interventions: explanation and elaboration. BMJ 2009;339:b2700.

32 Higgins J, Green S. Cochrane Handbook for systematic reviews of interventions. Chichester: John Wiley \& Sons, 2011.

33 Higgins JPT, Altman DG, Gøtzsche PC, et al. The Cochrane collaboration's tool for assessing risk of bias in randomised trials. BMJ 2011;343:d5928.

34 Cohen J. Statistical power analysis for the behavioral sciences. Routledge, 2013. ISBN: 1134742703

35 Borenstein M, Hedges LV, Higgins JP, et al. Introduction to meta-analysis. John Wiley \& Sons, 2011. ISBN: 1119964377

36 Guyatt GH, Oxman AD, Vist GE, et al. Grade: an emerging consensus on rating quality of evidence and strength of recommendations. BMJ 2008;336:924-6.

37 Tong HL, Coiera E, Laranjo L. Using a mobile social networking APP to promote physical activity: a qualitative study of users' perspectives. J Med Internet Res 2018;20:e11439.

38 Wyke S, Bunn C, Andersen E, et al. The effect of a programme to improve men's sedentary time and physical activity: the European fans in training (EuroFIT) randomised controlled trial. PLoS Med 2019;16:e1002736.

39 DiFrancisco-Donoghue J, Jung M-K, Stangle A, et al. Utilizing wearable technology to increase physical activity in future physicians: a randomized trial. Prev Med Rep 2018;12:122-7.

40 Pope Z. Use of wearable technology and social media to improve physical activity and dietary behaviors among college students: a 12-week randomized pilot study. University of Minnesota, 2018.

41 Vandelanotte C, Duncan MJ, Maher CA, et al. The effectiveness of a web-based Computer-Tailored physical activity intervention using Fitbit activity Trackers: randomized trial. J Med Internet Res 2018;20:e11321.

42 Ashton LM, Morgan PJ, Hutchesson MJ, et al. Feasibility and preliminary efficacy of the 'HEYMAN' healthy lifestyle program for young men: a pilot randomised controlled trial. Nutr J 2017;16:2.

43 Brakenridge CL, Fjeldsoe BS, Young DC, et al. Evaluating the effectiveness of organisational-level strategies with or without an activity tracker to reduce office workers' sitting time: a cluster-randomised trial. Int J Behav Nutr Phys Act 2016;13:115.

44 Finkelstein EA, Haaland BA, Bilger $M$, et al. Effectiveness of activity trackers with and without incentives to increase physical activity (TRIPPA): a randomised controlled trial. Lancet Diabetes Endocrinol 2016;4:983-95.

45 Poirier J, Bennett WL, Jerome GJ, et al. Effectiveness of an activity Tracker- and Internet-based adaptive walking program for adults: a randomized controlled trial. J Med Internet Res 2016;18:e34.

46 Ashe MC, Winters M, Hoppmann CA, et al. "Not just another walking program": Everyday Activity Supports You (EASY) model-a randomized pilot study for a paralle randomized controlled trial. Pilot Feasibility Stud 2015;1:4.

47 Cadmus-Bertram LA, Marcus BH, Patterson RE, et al. Randomized trial of a FitbitBased physical activity intervention for women. Am J Prev Med 2015;49:414-8.

48 Martin SS, Feldman DI, Blumenthal RS, et al. mActive: a randomized clinical trial of an automated mHealth intervention for physical activity promotion. J Am Heart Assoc 2015;4. doi:10.1161/JAHA.115.002239. [Epub ahead of print: 09 Nov 2015].

49 Thorndike AN, Mills S, Sonnenberg L, et al. Activity monitor intervention to promote physical activity of physicians-in-training: randomized controlled trial. PLoS One 2014:9:e100251.

50 Patel MS, Small DS, Harrison JD, et al. Effectiveness of behaviorally designed Gamification interventions with social incentives for increasing physical activity among overweight and obese adults across the United States: the step up randomized clinical trial. JAMA Intern Med 2019;9:1624-9.

51 Ellingson LD, Lansing JE, DeShaw KJ, et al. Evaluating motivational interviewing and habit formation to enhance the effect of activity Trackers on healthy adults' activity levels: randomized intervention. JMIR Mhealth Uhealth 2019;7:e10988.

52 Zhang J, Jemmott lii JB. Mobile app-based small-group physical activity intervention for young African American women: a pilot randomized controlled trial. Prev Sci 2019;20:863-72.

53 Patel MS, Volpp KG, Rosin R, et al. A randomized, controlled trial of Lottery-Based financial incentives to increase physical activity among overweight and obese adults. Am J Health Promot 2018;32:1568-75.

54 Robinson SA, Bisson AN, Hughes ML, et al. Time for change: using implementation intentions to promote physical activity in a randomised pilot trial. Psychol Health 2019;34:232-54.

55 Fanning J, Roberts S, Hillman CH, et al. A smartphone "app"-delivered randomized factorial trial targeting physical activity in adults. J Behav Med 2017;40:712-29.
56 Patel MS, Benjamin EJ, Volpp KG, et al. Effect of a Game-Based intervention designed to enhance social incentives to increase physical activity among families: the be fit randomized clinical trial. JAMA Intern Med 2017;177:1586-93.

57 John LK, Milkman KL, Gino F, et al. The role of incentive salience in habit formation. Harvard Business School, 2016: 16-90.

58 King AC, Hekler EB, Grieco LA, et al. Effects of three Motivationally targeted mobile device applications on initial physical activity and sedentary behavior change in midlife and older adults: a randomized trial. PLoS One 2016;11:e0156370.

59 Melton BF, Buman MP, Vogel RL, et al. Wearable devices to improve physical activity and sleep: a randomized controlled trial of College-Aged African American women. Journal of Black Studies 2016;47:610-25.

60 Patel MS, Asch DA, Rosin R, et al. Individual versus team-based financial incentives to increase physical activity: a randomized, controlled trial. J Gen Intern Med 2016:31:746-54.

61 Patel MS, Volpp KG, Rosin R, et al. A randomized trial of social comparison feedback and financial incentives to increase physical activity. Am J Health Promot 2016;30:416-24

62 Walsh JC, Corbett T, Hogan M, et al. An mHealth intervention using a smartphone APP to increase walking behavior in young adults: a pilot study. JMIR Mhealth Uhealth 2016;4:e109.

63 Cowdery J, Majeske P, Frank R, et al. Exergame Apps and physical activity: the results of the ZOMBIE trial. Am J Health Educ 2015;46:216-22.

64 Wang JB, Cadmus-Bertram LA, Natarajan L, et al. Wearable Sensor/Device (Fitbit one) and SMS Text-Messaging prompts to increase physical activity in overweight and obese adults: a randomized controlled trial. Telemed J E Health 2015:21:782-92.

65 Glynn LG, Hayes PS, Casey M, et al. Effectiveness of a smartphone application to promote physical activity in primary care: the smart move randomised controlled trial. Br J Gen Pract 2014;64:e384-91.

66 Guyatt GH, Oxman AD, Vist GE, et al. Grade: an emerging consensus on rating quality of evidence and strength of recommendations. BMJ 2008;336:924-6.

67 Goode AP, Hall KS, Batch BC, et al. The impact of interventions that integrate Accelerometers on physical activity and weight loss: a systematic review. Ann Behav Med 2017;51:79-93.

68 Fanning J, Mullen SP, McAuley E. Increasing physical activity with mobile devices: a meta-analysis. J Med Internet Res 2012;14:e161.

69 Foster C, Richards J, Thorogood M, et al. Remote and web 2.0 interventions for promoting physical activity. Cochrane Database Syst Rev 2013;9:Cd010395.

70 Palmer M, Sutherland J, Barnard S, et al. The effectiveness of smoking cessation, physical activity/diet and alcohol reduction interventions delivered by mobile phones for the prevention of non-communicable diseases: a systematic review of randomised controlled trials. PLoS One 2018;13:e0189801.

71 Direito A, Carraça E, Rawstorn J, et al. mHealth technologies to influence physical activity and sedentary behaviors: behavior change techniques, systematic review and meta-analysis of randomized controlled trials. Ann Behav Med 2017;51:226-39.

72 Williams SL, French DP. What are the most effective intervention techniques for changing physical activity self-efficacy and physical activity behaviour--and are they the same? Health Educ Res 2011;26:308-22.

73 Yardley L, Spring BJ, Riper H, et al. Understanding and promoting effective engagement with digital behavior change interventions. Am J Prev Med 2016;51:833-42.

74 McEwan D, Beauchamp MR, Kouvousis C, et al. Examining the active ingredients of physical activity interventions underpinned by theory versus no stated theory: a metaanalysis. Health Psychol Rev 2019;13:1-17.

75 Head KJ, Noar SM, lannarino NT, et al. Efficacy of text messaging-based interventions for health promotion: a meta-analysis. Soc Sci Med 2013;97:41-8.

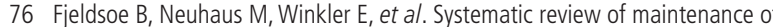
behavior change following physical activity and dietary interventions. Health Psychol 2011:30:99-109.

77 Short C, Rebar A, Plotnikoff R, et al. Designing engaging online behaviour change interventions: a proposed model of user engagement 2015.

78 Eysenbach G. The law of attrition. J Med Internet Res 2005;7:e11.

79 Tang MY, Smith DM, Mc Sharry J, et al. Behavior change techniques associated with changes in Postintervention and maintained changes in self-efficacy for physical activity: a systematic review with meta-analysis. Ann Behav Med 2019;53:801-15.

80 Ogilvie $\mathrm{D}$, Foster $\mathrm{CE}$, Rothnie $\mathrm{H}$, et al. Interventions to promote walking: systematic review. BMJ 2007;334:1204

81 Krebs P, Prochaska JO, Rossi JS. A meta-analysis of computer-tailored interventions for health behavior change. Prev Med 2010;51:214-21.

82 Chen JH, Asch SM. Machine Learning and Prediction in Medicine - Beyond the Peak of Inflated Expectations. N Engl J Med 2017;376:2507-9.

83 Topol EJ. High-Performance medicine: the convergence of human and artificial intelligence. Nat Med 2019;25:44-56.

84 Insel TR. Digital phenotyping: technology for a new science of behavior. JAMA 2017:318:1215-6.

85 Ekelund U, Tarp J, Steene-Johannessen J, et al. Dose-Response associations between accelerometry measured physical activity and sedentary time and all cause mortality: systematic review and harmonised meta-analysis. BMJ 2019;366:14570. 
86 Lee I-M, Shiroma EJ, Kamada M, et al. Association of step volume and intensity with all-cause mortality in older women. JAMA Intern Med 2019. doi:10.1001/ jamainternmed.2019.0899. [Epub ahead of print: 29 May 2019].

87 Global mobile consumer survey: UK cut | plateauing at the peak. The state of the smartphone. Deloitte 2019.

88 Global mobile consumer survey: US edition | a new era in mobile continues. Deloitte 2018.

89 Rodriguez JA, Clark CR, Bates DW. Digital health equity as a necessity in the $21 \mathrm{st}$ century cures act era. JAMA 2020;323:2381.
90 Bates DW, Landman A, Levine DM. Health Apps and health policy: what is needed? JAMA 2018;320:1975-6.

91 Gordon WJ, Landman A, Zhang $\mathrm{H}$, et al. Beyond validation: getting health apps into clinical practice. NPJ Digit Med 2020;3:14.

92 Patnode CD, Evans CV, Senger CA, et al. Behavioral counseling to promote a healthful diet and physical activity for cardiovascular disease prevention in adults without known cardiovascular disease risk factors: updated evidence report and systematic review for the US preventive services Task force. JAMA 2017;318:175-93.

$\underline{\underline{\sigma}}$

西 